\title{
educação

\section{Formação docente em processos de mudança: Análise de uma proposta de inovação curricular em cursos de licenciatura}

\author{
Elize Keller-FranCO \\ Centro Universitário Adventista de São Paulo, Brasil \\ Marcos Tarciso Masetto ${ }^{I I}$ \\ Pontifícia Universidade Católica de São Paulo, Brasil
}

\begin{abstract}
A recorrente denúncia de que a formação inicial não tem respondido às novas exigências do trabalho dos professores na sociedade contemporânea coloca em questão a revisão dos currículos que formam esses profissionais. Nesse contexto, o presente estudo tem como foco a análise crítica de uma organização curricular alternativa desenvolvida em cursos de licenciatura de uma universidade pública brasileira. Escolheu-se como questão orientadora investigar em que medida a proposta que vem sendo implementada nesses cursos traz referentes para inovação curricular na formação inicial de professores. Adota-se como caminho metodológico a abordagem qualitativa de pesquisa. Para obtenção dos dados privilegiouse a análise documental. A análise dos dados compreendeu três etapas: pré-análise; exploração do material; tratamento dos resultados obtidos e interpretação. Os dados indicam que a inovação curricular em andamento se manifesta com movimentos de mudança em um conjunto de elementos centrais e relevantes, tais como concepção e organização curricular, saberes docentes, modelos de formação, atividades práticas/ estágio e metodologia de ensino-aprendizagem.
\end{abstract}

Palavras-chave: Formação inicial de professores; Inovação curricular; Licenciaturas

\section{N T RO D U Ç Ã O}

Para Imbernón (2001), a educação das pessoas tem se tornado cada vez mais complexa em decorrência das mudanças radicais e vertiginosas nas estruturas científicas, sociais e educativas. Nesse contexto, não cabe mais a formação como simples transmissão do conhecimento acadêmico; é preciso educar para que as pessoas aprendam a conviver com a mudança e a incerteza. Das instituições educativas se espera que eduquem para a vida em toda a sua complexidade. Consequentemente, esses desafios repercutem na profissão docente. Para Imbernón (2001), essa realidade requer uma nova formação: "os docentes precisam desenvolver capacidades de aprendizagem da relação, da convivência, da cultura do contexto e de interação de cada pessoa com o resto do grupo, com seus semelhantes e com a comunidade que envolve a educação" (p. 18). 
Tais exigências afetam diretamente as instituições e os programas de formação docente. Que formação será necessária para o profissional que queremos? Que concepção e desenho curricular contribuiriam para tais objetivos? Será que os currículos que temos nos cursos de formação de professores conseguem responder às exigências do momento atual? Os paradigmas curriculares que os embasam são coerentes com as expectativas e desafios que se apresentam? Será que as mudanças que vêm sendo propostas no marco das legislações, a intensificação das pesquisas, dos estudos e das publicações da área e as transformações em curso na sociedade têm desencadeado formas inovadoras de formação?

Estudos mostram que se faz necessária uma mudança nos programas de formação de professores e que os problemas apontados vêm se repetindo há anos, sem que se façam alterações significativas (Diniz-Pereira \& Amaral, 2010; Gatti, 2010; Romanowski, 2010).

Com a intenção de contribuir com alguns elementos para repensar os currículos dos cursos de formação de professores, o presente artigo $^{1}$ traz para reflexão os dados de uma pesquisa que teve como campo de investigação a Universidade Federal do Paraná-Litoral (UFPR Litoral), instituição esta que vem buscando formas alternativas para organizar seu processo formativo.

\section{REFERENTES PARA A INOVAÇÃO CURRICULAR NA FORMAÇÃO INICIAL DE PROFESSORES}

Há um consenso em torno da necessidade de mudanças nos programas de formação de professores. Gatti (2010) refere que se tem falado muito em crise nas licenciaturas. Salienta que há décadas pesquisas vêm mostrando problemas nesses cursos; no entanto, tem sido proposta reformulação em um ou outro aspecto, não tocando no cerne da questão, que é a estrutura institucional e a distribuição dos seus conteúdos curriculares, conforme apontam as análises.

Ao fazer um balanço das condições atuais das licenciaturas, Romanowski (2010) constata que na maioria das instituições ocorreu o processo de reforma desses cursos. No entanto, as reformulações parecem orientar-se para reorganização das disciplinas que compõem a grade curricular, permanecendo a formação de professores atrelada à reprodução disciplinar de conteúdos descontextualizados em relação aos problemas da escola básica e trabalhados de modo fragmentado.

Essa realidade nos leva a indagar: qual o conjunto, o sentido e a direção das alterações que deve tomar uma inovação curricular na formação inicial de professores?

Cunha (2010) defende que:

Não é mais possível tratar das reformas de currículo simplesmente retirando, incluindo ou aumentando a carga horária das disciplinas. São necessárias mudanças que promovam a ampliação e o aprofundamento nos campos da ciência, da arte e da técnica, sem desconhecer que é fundamental tratar, também, dos aspectos epistemo-metodológicos que envolvem as relações entre prática e teoria, a introdução de perspectivas interdisciplinares, a promoção do pensamento crítico, a criatividade, a capacidade de resolver problemas, de unir ensino e pesquisa como indicadores de melhoria da qualidade do ensino superior. (p. 139)

\footnotetext{
${ }^{1} \mathrm{O}$ artigo amplia parte de uma pesquisa publicada em Keller-Franco e Masetto (2017), na qual se analisa a concepção de currículo presente na proposta da UFPR Litoral. O presente estudo apresenta os dados da análise do paradigma curricular na proposta educativa, nas dimensões dos saberes docentes, componentes práticos/estágios, modelos de formação e aspectos metodológicos.
} 
Complementando os direcionamentos propostos por Cunha (2010) para uma inovação curricular na formação inicial de professores, Imbernón (2001), ao se referir às novas tendências para a formação docente, propõe:

Uma reestruturação da formação de professores precisa se opor frontalmente a toda manifestação explícita ou oculta da racionalidade técnica que, com outros nomes e procedimentos, nos leva de volta ao passado (competências, planos estratégicos, qualidade, eficiência, eficácia...), sem análise, seja nos conteúdos curriculares ou nas formas de gestão, seja no controle técnicoburocrático da educação e da formação. É preciso assumir uma perspectiva crítica em educação e formação. (p. 37)

Para o autor, as mudanças em curso na sociedade apontam para importantes elementos que influenciam na formação de professores, tais como o questionamento da pura transmissão nocionista e conceitual do conhecimento, a importância do trabalho em equipe e de formas colegiadas, novas metodologias de formação, o fator da diversidade e da contextualização como elementos imprescindíveis na formação, o questionamento de práticas uniformizantes e a valorização da formação a partir de dentro, na própria instituição ou no contexto próximo a ela. Carbonell (2002) aposta nas pedagogias progressistas, cujas marcas são: ênfase na cooperação e na democracia participativa; compromisso com a transformação escolar e social; vinculação estreita com o entorno; concepção integrada e globalizada do conhecimento; luta pela igualdade social e respeito à individualidade.

Dessa forma, considera-se que o paradigma curricular técnico-disciplinar vem se mostrando inadequado para articular o conjunto de alterações necessárias para uma inovação na formação de professores. Na busca de novas formas de conceber a formação de professores, concordamos com Masetto (2012), para quem a inovação envolve inevitavelmente a utilização de abordagens curriculares diferentes das habitualmente usadas.

A mudança que se faz necessária remete para a construção de projetos que promovam a reconstrução do currículo em face das dificuldades diagnosticadas e dos horizontes que há tempos vêm se descortinando. $\mathrm{Na}$ sequência, busca-se levantar referentes para a inovação na formação inicial de professores a partir da análise de um projeto em cursos de licenciatura com movimentos de mudança.

\section{MOVIMENTOS DE MUdANÇA: INTERPRETANDO A INOVAÇÃO C U R R I C U L A R}

A UFPR Litoral iniciou suas atividades em 2005. Localizada no município de Matinhos, tem como propósito contribuir para o desenvolvimento socioeconômico, cultural e educacional da região litorânea do Paraná e Vale do Ribeira. Os primeiros cursos de licenciatura foram criados em 2008. A universidade compreende que a proposta de desenvolvimento sustentável para a região implica na promoção da educação em todos os níveis educacionais. Assim, considera ser fundamental a formação de professores para viabilização desse novo projeto

A implantação das licenciaturas ocorreu a partir de um estudo das áreas que apresentavam carência de docentes na região. Esse estudo orientou a criação de três cursos. Em 2008, iniciaram-se os cursos de Licenciatura em Ciências e Licenciatura em Artes e, em 2009, a Licenciatura em Linguagem e Comunicação. A proposta das licenciaturas está em sintonia com o Projeto Pedagógico Institucional, seguindo nova forma de conceber e organizar seu processo 
educativo. No atual contexto educacional, em que redundam defesas em torno de mudanças e onde são raras as experiências concretas de mudança, pareceu relevante investigar uma experiência em andamento com características de inovação. Nesse estudo situamos a interpretação da inovação no plano da sua conceitualização com base na análise documental, utilizando os procedimentos metodológicos propostos por Lüdke e André (2013), a saber: pré-análise, contemplando a escolha dos documentos; exploração dos mesmos, seguida de leituras sucessivas destes; e levantamento de temáticas e categorias em diálogo com o referencial teórico.

$\mathrm{Na}$ seleção dos materiais para análise foram priorizados os documentos a seguir, todos da UFPR Litoral, por julgar-se que eles compõem, de forma mais completa, a apresentação da proposta à qual se dirige essa investigação, atendendo, assim, aos critérios de pertinência e adequação: Projeto Político Pedagógico Institucional (UFPR, 2008); Projeto Político Pedagógico do Curso de Licenciatura em Ciências (UFPR, 2010a); Projeto Político Pedagógico do Curso de Licenciatura em Artes (UFPR, 2010b); Projeto Político Pedagógico do Curso de Licenciatura em Linguagem e Comunicação (UFPR, 2011).

Selecionados os documentos, procedeu-se à análise propriamente dita dos dados, com a exploração do material, mediante um processo de sucessivas leituras, num movimento dinâmico de interlocução entre teoria e empiria. Após a obtenção de um conjunto inicial de categorias, voltou-se novamente ao material para aumentar a compreensão, descobrir novos ângulos e ampliar a visão. Reavaliou-se ainda as ligações entre as várias categorias, buscando estabelecer relações e associações para então combinálas e reorganizá-las. Em uma nova etapa de exploração do material, foram sublinhados nos textos as frases e parágrafos que expressavam ideias que mostravam ter relevância no bojo das categorias e no assunto em discussão. E, por fim, se procedeu ao tratamento dos resultados obtidos e interpretação, em que os recortes significativos de cada texto em diálogo com o referencial teórico e com os objetivos propostos para a pesquisa ofereceram as bases para a análise interpretativa. A interlocução se deu com autores que têm discutido o currículo e a formação docente (Diniz-Pereira, 2007; Diniz-Pereira \& Amaral, 2010; García, 1999; Gatti, 2010; Giroux, 1997; Imbernón, 2001; Lopes \& Macedo, 2011; Silva, 2007; Tardif, 2011).

Do diálogo entre a empiria e a teoria brotaram as seguintes categorias como indicadores para análise da inovação: paradigma curricular, saberes docentes, formação prática/estágio, modelos de formação e metodologias de ensinoaprendizagem.

\subsection{PARA Digma CURRICULAR}

Abordamos a análise do paradigma curricular em dois planos: orientação conceitual e organização estrutural, pois é comum observarmos iniciativas de inovação curricular que se concentram em apenas um desses planos. Em alguns casos adota-se um discurso inovador, mas mantém-se uma estrutura curricular que inviabiliza o alcance dos princípios propostos, como, por exemplo, o discurso da interdisciplinaridade em um desenho curricular disciplinar, ou, então, se altera o desenho do currículo buscando um verniz de inovação, mas conserva-se o paradigma antigo. Defendemos que uma inovação curricular pressupõe coerência entre a concepção e o desenho curricular.

Silva (2007) organiza as abordagens curriculares em três grandes linhas: teorias tradicionais, teorias críticas e pós-críticas. KellerFranco (2014), com base em Silva (2007) e Lopes e Macedo (2011), apresenta um resgate histórico do desenvolvimento curricular. Localiza nos anos 70 a emergência de um importante movimento denominado de teorias curriculares 
críticas como uma reação à concepção curricular tradicional dominante, de ênfase tecnicista, burocrática e administrativa, inspirada nos modelos de administração taylorista. As teorias curriculares críticas deslocam a ênfase centrada nos aspectos técnicos de como organizar e elaborar o currículo limitada ao âmbito pedagógico, ampliando a análise para uma perspectiva sociológica em suas determinações e conexões com as estruturas econômicas e sociais mais amplas e com as relações de poder. O currículo passa a ser visto como uma construção social, na medida em que os arranjos curriculares decorrem de uma seleção sobre modelo de ser humano, modelo de sociedade e tipo de conhecimento, que, por uma contingência social e histórica, se tornaram consolidados como currículo. As teorias curriculares pós-críticas dão continuidade às teorias críticas, ampliando a análise de poder a que o currículo está submetido para além das relações econômicas, incluindo a homogeneização cultural.

A análise do currículo da UFPR Litoral no plano conceitual revela que a instituição não faz opção explícita por um determinado paradigma curricular; contudo, é possível observar que a descrição das finalidades e da organização educativa trazem um conjunto de elementos que permite relacioná-los aos paradigmas curriculares crítico e pós-crítico, em contraposição ao paradigma tradicional fundado na racionalidade técnica.

Com a crise do paradigma dominante abrem-se possibilidades para questionamentos e reflexões da formação que foi historicamente nele inspirada. Portanto, deixa de ser natural a construção de um currículo a partir, somente, de um olhar técnico da área de conhecimento que envolve. Da mesma forma, é possível questionar a compreensão da docência e da discência especialmente na dimensão técnica. $O$ conhecimento passa a ser compreendido não mais por sua exatidão, mas por sua complexidade. O conhecimento, ao assumir a dimensão de construção científico-social, estende essa reflexão também para o trabalho acadêmico nas suas diversas manifestações. No exercício da docência universitária, a condição instrumental baseada na racionalidade técnica tem sua condição abalada, pois não carrega mais o efeito messiânico da incondicional resolução de problemas. Nessa mesma perspectiva, a universidade, proveniente da lógica da modernidade, se coloca em igual crise, pelo questionamento de seu papel, também visto como messiânico, como principal fonte produtora de conhecimentos, gerando uma crise institucional e de legitimidade. A proposição do Projeto Político-Pedagógico do Setor Litoral da UFPR quer superar os pressupostos da modernidade e lançar-se na construção de um projeto inovador e emancipatório. (UFPR, 2008, p. 6)

Um ponto central para uma teoria curricular crítica é sua finalidade emancipatória. Para Lopes e Macedo (2011), numa perspectiva emancipatória o currículo proporciona atividades pedagógicas que incluem a busca da superação das injustiças sociais, políticas e econômicas, bem como das relações excludentes, considerando os estudantes como sujeitos ativos nas experiências de aprendizagem na escola, para além do espaço escolar, sujeitos comprometidos com a ação transformadora. Exercem uma importante influência nas alternativas curriculares emancipatórias no Brasil os estudos de Inês Barbosa de Oliveira. A autora defende emancipação por meio de uma epistemologia que se pretende política a partir dos estudos do cotidiano. Oliveira (2004) refere que é pela valorização de práticas emancipatórias, criadas nos espaços e fazeres cotidianos no interior das instituições educativas por meio dos seus currículos e da ação dos seus educadores, que pode ser desenvolvida uma pedagogia da emancipação. É defendido pela autora que a institucionalização de experiências voltadas 
para um conhecimento-emancipação pode se ampliar para processos sociais emancipatórios. Em diálogo com Oliveira (2004, 2005), Lopes e Macedo (2011) defendem que "um projeto é emancipatório na relação comparativa que se estabelece com o que nos regula socialmente, não como um padrão absoluto a ser alcançado" (p. 179).

A finalidade emancipatória está na gênese da UFPR Litoral, que nasce com o intuito de atuar na realidade concreta do litoral paranaense e Vale do Ribeira, trazendo para essas regiões e para as pessoas que ali vivem desenvolvimento socioeconômico, cultural e pessoal.

Nessa direção, defende-se a construção coletiva de um projeto político pedagógico emancipatório com a centralidade no combate da resignação e naturalização do sofrimento e exclusão social, a partir da leitura crítica da realidade que se constitui como ponto de partida e de retorno para a construção e reconstrução do conhecimento. (UFPR, 2008, p. 8)

Para isso, funda-se em um projeto formativo comprometido com ideais e valores advindos de uma concepção de educação anti-hierárquica e anti-exclusivista que não privilegia uma minoria:

Há o desafio para a universidade de exercitar o seu papel social de questionador crítico e fomentador de conhecimentos que dialoguem e interfiram propositivamente na realidade social e econômica em que se insere. É preciso diminuir os processos excludentes do contexto em que vivemos, onde o mundo do trabalho e suas radicais transformações são evidências incontestáveis. Cabe então a universidade questionar e fazer a sociedade refletir sobre que tipo de homem [sic] e de sociedade quer construir. (UFPR, 2008, p. 5)

Nesta perspectiva, há uma reconhecida afinidade entre os propósitos da educação emancipatória da UFPR Litoral, voltada para a transformação social, e os conceitos de poder, emancipação e libertação desenvolvidos por Michel Apple (2003), Henry Giroux (1997) e Paulo Freire (2005), expoentes da teorização curricular crítica.

A UFPR Litoral busca uma pedagogia contrahegemônica que, como propõe Giroux (1997), "não apenas fortalece os estudantes ao dar-lhes o conhecimento e habilidade sociais necessários para poderem atuar na sociedade mais ampla como agentes críticos, mas também os educa para a ação transformadora" (p. 28). Como propõe Anyon (2011), desenvolver a consciência crítica por si só não é suficiente para envolver os alunos na busca pela justiça social; dentre outros aspectos, é necessário um currículo adequado com oportunidades para o desenvolvimento de si mesmos como agentes atuantes. O projeto em análise perspectiva a formação de pessoas proativas e autônomas, capazes de, no exercício cotidiano de suas ações pessoais e profissionais, exercitarem relações de respeito, valorização e compromisso com todos e todas. Ao colocar em ação os princípios de uma teoria curricular crítica com fins emancipatórios, a proposta desenvolvida nas licenciaturas da UFPR Litoral representa um avanço para a formação de professores, pois, conforme Giroux (1997), "os programas de educação de professores poucas vezes estimulam os futuros professores a assumirem seriamente o papel do intelectual que trabalha no interesse de uma visão de emancipação" (p. 198).

$\mathrm{Na}$ continuidade da análise do currículo, encontra-se também propósitos relacionados às teorias curriculares pós-críticas que ampliam a visão de poder a que o currículo está submetido. Essas teorias trazem para o debate o multiculturalismo, as relações de gênero, raça e etnia, o imperialismo econômico e cultural colonial e pós-colonial, entre outros. Nessa perspectiva, o currículo não se limitaria a defender a tolerância e o respeito à 
diversidade cultural, mas traria para reflexão as relações de assimetria e desigualdades que geram as diferenças. Conforme Silva (2007), a abordagem multicultural defende que promover a igualdade vai além de oferecer igualdade de acesso ao currículo hegemônico, implicando uma transformação substantiva do currículo dominante para promover uma equivalência entre as diferentes manifestações culturais. Considerase ainda como um currículo culturalmente inclusivo aquele capaz de democratizar os conhecimentos produzidos pelas diversas ciências no sentido de o tornar efetivamente acessível a todos/as, independentemente do seu universo cultural.

O currículo das licenciaturas da UFPR Litoral é representativo da materialização de uma abordagem curricular multiculturalista mediante seu desenho curricular constituído de três eixos: as Interações Culturais e Humanísticas (ICH), os Projetos de Aprendizagem (PA) e os Fundamentos Teórico-Práticos (FTP).

As ICH são espaços por excelência para atender essa abordagem. São constituídas por oficinas propostas por alunos, membros da comunidade externa, professores e demais membros da comunidade acadêmica, envolvendo saberes que compõem a cultura da região. Os alunos escolhem as oficinas em que querem participar, formando grupos de diferentes cursos e semestres. Nesse espaço, encontram lugar para socializar e divulgar a sua cultura, bem como para conhecer, interagir com outros saberes culturais, populares e pessoais, valorizando culturas, pessoas e saberes. Além de ser um espaço de trocas, possibilita a reflexão crítica acerca das suas identidades, das suas formações e do seu papel social enquanto indivíduos e coletividade. Nesse movimento, as diferentes culturas não negam as diferenças entre uma visão e outra; o que elas negam é a invasão de uma pela outra, o que elas afirmam é o indiscutível subsídio que uma dá a outra (Freire, 2005).
Para garantir a dimensão pedagógica deste eixo, as interações devem ser construídas simétrica e dialogicamente entre estudantes, comunidades e servidores, valorizando os diferentes saberes e lugares culturais que compõem a vida social. Problematizando/questionando as hierarquias existentes entre estes diferentes saberes e culturas, fortalecendo compromissos éticos e políticos para além daqueles valorizados na lógica do mercado, visando à vivência e ao adensamento de relações autogestionárias, ou seja, relações em que o grupo cuida diretamente de seus próprios deveres e interesses, com ampla liberdade de organização, desde que respeitando as diretrizes do eixo pedagógico de Interações Culturais e Humanísticas. (UFPR, 2010a, p. 45; UFPR, 2011, p. 15)

Os demais espaços curriculares - os Projetos de Aprendizagem e os Fundamentos Teóricos e Práticos - também atendem a uma abordagem multiculturalista. Nos FTPs, a perspectiva cultural da região e das pessoas constitui um dos saberes que se articula aos demais:

Nos fundamentos teórico-práticos, almejase a integração entre os saberes artísticos (Artes Visuais, Dança, Música e Teatro) com as práticas pedagógicas e com outros saberes... Este projeto curricular procura, ainda, tomar como ponto de partida o contexto no qual o curso está inserido, a história de vida dos professores em formação, matrizes culturais a partir das quais as vidas desses estudantes foram construídas, seus desafios, e suas particularidades em articulação com a realidade social. (UFPR, 2010b, p. 39)

Nos PAs os estudantes são convidados a perceber criticamente a realidade, compreender os diversos aspectos que a estruturam e estabelecer ações em que a busca de conhecimento se encontra com situações da realidade local, configurando relações entre pessoas, saberes e instituições. 
Dialogar com a realidade concreta e com o sistematizado, tendo como ponto de partida a pesquisa instaurada pelos projetos de aprendizagem, possibilitará aos discentes, docentes, técnicos e comunidade desencadear um processo de formação cultural crítico, porque exigirá a exposição de posições e de compreensões de conhecimento, tensionadas constantemente pelas realidades distintas dos sujeitos desse processo, em um devir histórico. (UFPR , 2008, p. 12)

Dirigindo a análise para o plano da organização curricular, observa-se que um passo significativo foi dado no sentido de superar a estrutura disciplinar. Ao invés de disciplinas, os espaços curriculares de aprendizagem estruturam-se em três eixos: os Projetos de Aprendizagem, os Fundamentos Teórico-Práticos e as Interações Culturais e Humanísticas.

Os Projetos de Aprendizagem ocupam um a dois dias da semana. Nesse espaço, os alunos desenvolvem projetos que ampliam a aprendizagem, aliando os interesses pessoais com as necessidades da comunidade, orientados por professores que os estimulam e desafiam a construir processos autônomos na busca do conhecimento.

Os Fundamentos Teórico-Práticos ocupam um a três dias e são selecionados com base nas diretrizes curriculares de cada curso e nos saberes necessários à execução dos projetos de aprendizagem. Eles são organizados por módulos que contemplam uma abordagem integrada e contextualizada do conhecimento.

As Interações Culturais e Humanísticas ocupam um a dois dias da semana. Esse componente curricular visa possibilitar a sensibilização, a compreensão e a valorização da cultura local e articular os saberes científicos, culturais e pessoais.

Além dos eixos, o currículo se organiza em fases com focos norteadores:

- $1^{\mathrm{a}}$ Fase: Conhecer e Compreender -
Compreensão crítica da realidade (um a dois semestres);

- $2^{\mathrm{a}}$ Fase: Compreender e Propor Aprofundamento metodológico-científico (um a quatro semestres);

- $\quad 3^{a}$ Fase: Propor e Agir - Transição para o exercício profissional (um a dois semestres).

A organização curricular das licenciaturas reflete com clareza o ideal de uma abordagem integrada de formação:

A concepção do processo educativo fundada na realidade social demanda um currículo integrado, flexível e articulado, rompendo com a concepção disciplinar e fragmentada, e trabalhando com espaços de formação pautados na realidade concreta do meio em que os estudantes estão inseridos. (UFPR, 2010b, p. 37)

Bernstein (1995) distingue dois tipos de organização curricular: o currículo coleção e o currículo integração. O currículo coleção corresponde ao modelo disciplinar, a forma mais usual da organização curricular composta por um conjunto de disciplinas justapostas que não mantêm comunicação entre si. O currículo integração pressupõe uma articulação dos saberes de diversas áreas a determinados temas gerais e maior participação por parte de professores $\mathrm{e}$ alunos no processo de planejamento curricular. $\mathrm{O}$ autor buscou analisar como as diferentes estruturas curriculares atendem a diferentes princípios de poder e controle, criando os conceitos de 'classificação' e 'enquadramento' para analisar as relações estruturais do currículo.

As licenciaturas da UFPR Litoral podem ser classificadas próximo à integração curricular, apresentando baixa classificação (superação do isolamento entre as áreas do conhecimento) e baixo enquadramento (elevado espaço para participação de professores e alunos). Esses aspectos são claramente percebidos na Proposta Pedagógica dos cursos que apresentam 
como diferencial o caráter interdisciplinar e a aprendizagem centrada em projetos. Destaca-se que a proposta pedagógica fundamentada em projetos tem nesses o principal potencializador da integração curricular, sendo que os projetos contribuem para a baixa classificação ao promover a integração do conhecimento, bem como para o baixo enquadramento, ao favorecer a participação ativa de alunos e docentes na construção do conhecimento.

A concepção do processo educativo fundado na realidade social exige a organização de um currículo flexível, de forma articulada e com múltiplas relações. Rompe com a concepção disciplinar e fragmentada para trabalhar com espaços de formação que têm como principal articulador os projetos de aprendizagens, originados na realidade concreta do meio em que estão inseridos. Esses projetos possibilitam o diálogo com os fundamentos teórico-práticos, que empiricamente já os constituem. Esse diálogo se expande ao abarcar as interações culturais e humanísticas que se apresentam como espaços para a troca com pessoas da comunidade externa, de outros cursos, de outras realidades, e também como possibilidade de síntese e reflexão de sua formação e de seu papel social. (UFPR, 2010a, p. 9; UFPR, 2010b, p. 17; UFPR, 2011, p. 9).

A interdependência entre o desenho curricular e os fundamentos e princípios que lhe dão suporte é um requisito fundamental para o sucesso de uma inovação no campo do currículo. A mudança nos cursos de formação de professores da UFPR Litoral traz indicadores de um projeto formativo que apresenta coerência entre a concepção e o desenho curricular ao situar-se no marco conceitual das teorias curriculares críticas e pós-críticas e nos pressupostos organizativos do currículo integrado, o que vem sendo associado à perspectiva crítica (Beane, 2003; Lopes \& Macedo, 2011; Santomé, 1998).
A análise do paradigma que orienta o currículo das licenciaturas da UFPR Litoral revela que o mesmo rompe com o paradigma técnicodisciplinar e que compartilha afinidade notável com os princípios das teorias curriculares críticas e pós-críticas e os pressupostos do currículo integrado. No entanto, não gostaríamos de 'enquadrá-lo' em uma determinada tendência curricular, pois a análise documental sugere que estamos diante de uma perspectiva curricular de longo alcance. Não existe uma perspectiva única que explique, totalmente, as direções e os sentidos da reforma curricular, colocando-nos diante da possibilidade um novo paradigma curricular.

\subsection{SABERES DOCENTES}

Uma das questões que tem ocupado o centro dos debates sobre as mudanças nos programas de formação dos professores referese aos saberes docentes. Tardif (2011) destaca o amplo movimento realizado nos últimos anos em torno da profissionalização docente e o papel de destaque concedido à renovação dos fundamentos epistemológicos de base da profissão.

Como a inovação analisada tem respondido às propostas de atualização dos conteúdos da formação inicial de professores? Como tem contemplado os diferentes tipos de conhecimentos propostos para os professores em formação?

Recorremos às ementas expressas nos Projetos Pedagógicos para verificar como os diferentes componentes do conhecimento de base para a formação de professores estão sendo considerados nos cursos analisados. Para a análise adotou-se a tipologia proposta por García (1999), por incluir o conhecimento do contexto como componente do saber docente; os demais autores o incorporam como um tema dentro das tipologias. Considerando que uma 
das necessidades é formar professores para influir na realidade em que vão atuar, a inclusão do conhecimento do contexto nos programas de formação é um dos aspectos que precisa ser contemplado.

García (1999) apresenta os seguintes componentes do conhecimento profissional dos professores: conhecimento psicopedagógico envolvendo temas relacionados com o ensino, a aprendizagem e os alunos; conhecimento do conteúdo contemplando o conhecimento substantivo, que inclui o corpo de conhecimentos de uma área, e o conhecimento sintático, que diz respeito ao domínio que o professor tem das tendências, linhas, perspectivas e paradigmas em jogo no seu campo de especialidade e na pesquisa da área; conhecimento didático do conteúdo, combinando o conhecimento da matéria e o pedagógico; e, finalmente, conhecimento do contexto, incluindo a conscientização e a valorização dos aspectos socioeconômicos e culturais da região e as oportunidades que oferecem para o currículo. Deve estenderse, também, ao conhecimento da realidade em nível nacional e internacional, bem como a competências didáticas para integrar esses conhecimentos nas unidades didáticas e projetos curriculares. Inclui, ainda, o conhecimento da escola e da sua cultura, dos alunos e professores.

Do ponto de vista inovador, pode-se dizer que a reforma investigada busca nova articulação e equilíbrio no que tange aos saberes de base para a formação dos profissionais da educação.

O Projeto Pedagógico do Curso de Ciências (UFPR, 2010a) declara que a formação para a docência é o eixo central do curso, não havendo dicotomia entre conhecimentos pedagógicos e conhecimentos específicos. Os conhecimentos pedagógicos são transversais ao curso, devendo dialogar com os conhecimentos específicos integralmente. $\mathrm{O}$ curso de Linguagem e Comunicação propõe que a construção dos saberes necessários às práticas educativas se dê a partir de relações interdisciplinares (UFPR, 2011). O Projeto Pedagógico do Curso (PPC) de Artes (UFPR, 2010b) apresenta a organização dos Fundamentos Teórico-Práticos em módulos que contemplam de forma integrada eixos conceituais, estruturais, integrador e pedagógico.

$\mathrm{Na}$ análise realizada sobre o conteúdo das ementas, nota-se que são contempladas as variadas tipologias do conhecimento indicadas por García (1999) para uma ressignificação nos cursos de formação inicial de professores. Selecionamos algumas ementas para representar de forma interpretativa o equilíbrio entre os vários componentes dos saberes docentes.

MÓDULO: Seminário em Prática de Ensino de Artes

EMENTA: Discussão sobre temas contemporâneos do Ensino das Artes. O histórico do ensino das Artes no Brasil. As influências internacionais assimiladas. Propostas contemporâneas para o Ensino das Artes. O papel das artes na escola. A formação do professor de artes. (UFPR, 2010b, p. 83)

Nota-se que o tema "O histórico do ensino de artes no Brasil" contempla tanto a dimensão referente ao conhecimento do conteúdo como ao conhecimento do contexto, revelando uma articulação entre as diversas tipologias do conhecimento.

A presença das várias dimensões do conhecimento de base para a profissão docente também se encontra na Licenciatura em Ciências:

UNIDADE DIDÁTICA: "Ciências da Natureza e Educação"

EMENTA: História da Terra. Interpretação dos fenômenos da natureza e dos astros para a compreensão de como a sociedade intervém, utilizando os recursos e criando um novo meio social e tecnológico. Compreensão das diferentes organizações da vida em sociedade em diversas 
culturas, priorizando a cultura local, a partir da história da astronomia. A construção da Ciência da Astronomia e suas determinações/implicações históricas e sociais. Metodologias de Ensino para estudo dos fenômenos da natureza e dos astros nas escolas regionais. Gestão de processos e práticas pedagógicas na educação básica. (UFPR, 2010a, p. 54)

No módulo "Ciências da Natureza e Educação" encontram-se articulados conhecimentos relativos ao conteúdo (História da Terra, fenômenos da natureza e dos astros); conhecimento didático do conteúdo (metodologias de ensino para estudo dos fenômenos da natureza e dos astros nas escolas regionais); conhecimento pedagógico geral (processos e práticas pedagógicas na educação básica) e conhecimento do contexto (interpretação dos fenômenos da natureza e dos astros para a compreensão de como a sociedade intervém, utilizando os recursos e criando um novo meio social e tecnológico. Compreensão das diferentes organizações da vida em sociedade em diversas culturas, priorizando a cultura local, a partir da história da astronomia). Esta integração é também observada no nome da unidade didática.

Em Linguagem e Comunicação, encontra-se igualmente a valorização dos vários componentes do saber docente:

DISCIPLINA: Introdução aos Estudos Linguísticos

EMENTA: A construção da Linguística como ciência: estudo crítico da constituição e circulação desse saber, sua relação com outras áreas de conhecimento e implicações no ensino da Língua Portuguesa. Campos da Linguística. Linguagem e sociedade. Variação linguística. Implicações entre objeto e método. (UFPR, 2011, p. 87)

$\mathrm{Na}$ ementa do componente curricular
"Introdução aos Estudos Linguísticos", percebe-se uma abordagem integrada entre os conhecimentos do conteúdo e o conhecimento pedagógico geral (a construção da linguística como ciência e implicações no ensino da Língua Portuguesa). Não ficaram clarificados os conhecimentos didáticos do conteúdo e do contexto, mas considera-se que os quatro componentes não precisam estar presentes em todas as ementas; apenas será preciso haver um equilíbrio dos componentes do saber docente ao longo do curso.

Nesse curso, a análise das ementas permite observar um movimento de transição entre a transformação e a conservação. Embora se observe uma tendência para a valorização de novos saberes, observa-se, também, a permanência de ementas no paradigma tradicional, com predomínio dos saberes relativos ao conteúdo, como exemplificado abaixo:

CURSO: Licenciatura em Linguagem e
Comunicação
DISCIPLINA: Estudos Literários e Ensino I
EMENTA: Concepções de Literatura. Poética
Clássica. Formas da narrativa - Epopeia. Drama -
tragédia e comédia. Romance. (UFPR, 2011, p. 96)

Pela análise das ementas dos três cursos, é possível sintetizar os seguintes aspectos que se apresentam como desejáveis e atuais na formação dos professores: integração dos diferentes saberes docentes; valorização do conhecimento do contexto, uma vez que os programas de formação de professores têm prestado pouca atenção ao contexto social, político e cultural da escola, do seu entorno e da sociedade; abordagem multirreferencial para a articulação dos saberes em uma perspectiva de ruptura epistemológica que leva em consideração as experiências de vida dos alunos e a constituição de novos espaços de aprendizagem para além dos muros da universidade; processo formativo 
que valoriza a prática desde o começo do curso, ao articular os saberes relativos ao conteúdo, os saberes pedagógicos gerais e os saberes didáticos do conteúdo; nomenclatura dos módulos reatualizada de forma que favoreça a integração e a inclusão das diversas tipologias do conhecimento.

\subsection{FormaÇão PRÁt ICA/ESTÁgIO}

Estudos revelam que os componentes de formação prática recebem uma importância secundária nos programas de formação. Gatti e Nunes (2009), reportando-se a cursos de licenciatura, observaram que os estágios apresentam imprecisões que vão desde as atividades desenvolvidas e objetivos até à forma de acompanhamento e validação dessas atividades, bem como convênios e parcerias com os campos de estágio.

A inovação analisada sinaliza para uma transformação dos estágios. Os Projetos Pedagógicos dos três cursos dedicam um capítulo às orientações, normatizações, atribuições dos envolvidos e finalidades relativas aos estágios.

Os cursos dispõem de uma Comissão Orientadora de Estágio (COE) que tem como responsabilidade mediar todas as relações entre os estudantes e os campos de estágio. Os alunos elaboram um plano contendo atribuições e atividades do estagiário no âmbito da instituição campo, estudo de reconhecimento institucional, leituras que subsidiarão os estudos e projeto de intervenção.

A avaliação do estágio prevê um processo contínuo, envolvendo responsabilidade, ética nas ações desenvolvidas, competência teóricometodológica, capacidade de articulação entre os conhecimentos produzidos em sala e a vivência em campo, postura acadêmicoprofissional durante o processo, relatórios, resenhas, artigos, portefólios, seminários parciais e finais das atividades desenvolvidas, sendo de responsabilidade do estudante, do professor orientador e do supervisor de campo.

O estágio se realiza em contextos formais e não formais de ensino, com parceria devidamente firmada, promovendo a articulação entre a universidade, o Núcleo Regional de Educação de Paranaguá e as Secretarias Municipais de Educação. Constituem ainda campos de estágio as ONGs, movimentos sociais, classes em assentamentos, canteiros de obras, instituições de caráter sociocultural, instituições de educação a distância (EAD) e outras situações de docência. Cada orientador de estágio poderá ter, no máximo, quinze orientandos.

As ementas permitem antever um programa intencional de estágio:

CURSO DE LICENCIATURA EM CIÊNCIAS BIOLÓGICAS

UNIDADE DIDÁTICA: Estágio Supervisionado IV

EMENTA: Atividades de análise das dimensões administrativas e organizacionais da escola, acompanhamento dos processos de planejamento, relação escola comunidade, observação de atividades extraclasse, entrevistas com professores, alunos, equipe pedagógica e comunidade, análise de produções de alunos, análise de situaçõesproblema, estudos de caso, entre outras atividades. Produção da monografia, na qual se encontram as metodologias de investigação aplicadas, os achados da pesquisa, os pontos de reflexão e os desdobramentos desta. (UFPR, 2010a, p. 71)

CURSO DE LICENCIATURA EM LINGUAGEM E COMUNICAÇÃO

UNIDADE DIDÁTICA: Estágio Supervisionado I

EMENTA: Caracterização da relação espaço/ tempo em instituições de ensino. Caracterização da estrutura e funcionamento das instituições de ensino. Análise dos processos de interação entre a comunidade escolar e das relações de poder na 
escola. Realização de Fórum Final de Estágio.

UNIDADE DIDÁTICA: Estágio Supervisionado II

EMENTA: Caracterização de instituições não escolares (ONGs, Projetos e Programas Educacionais, Associações, Movimentos Sociais). Análise das relações de poder que se estabelecem entre os diversos espaços institucionais escolares e não escolares. Realização de Fórum Final de Estágio Curricular. (UFPR, 2011, p. 102)

Observa-se que o estágio nas licenciaturas da UFPR Litoral apresenta um cenário diferente ao apontado nas pesquisas. $\mathrm{O}$ mesmo encontrase concebido e normatizado de forma bastante clara e completa nos Projetos Pedagógicos dos cursos. Convém destacar que a concepção que os orienta apresenta coerência com a perspectiva de uma epistemologia da prática. O estágio deixa de ser considerado apenas como um apêndice do currículo para ocupar o lugar de um importante componente formativo desenvolvido de forma articulada com o processo de formação e com a realidade local, proporcionando a construção integrada dos conhecimentos científico, social, cultural e da docência.

Art. $9^{\circ}$ - ... as atividades de Estágio Supervisionado visam à inserção gradativa do profissional em formação nos processos escolares, devendo abarcar três situações, que, embora distintas, não são lineares, ou seja, é desejável que se desenvolvam dialeticamente, por meio da ação/reflexão/ação nos espaços e processos da escola campo. Está implícita em todos os momentos a observação, o diálogo, a pesquisa, a ação e o aprofundamento teórico.

INSERÇÃO I - envolve atividades relacionadas com o diagnóstico do contexto social em que se organiza o trabalho pedagógico, bem como a análise das correlações que se estabelecem entre o cotidiano das organizações escolares, a comunidade interna e externa e as exigências da sociedade contemporânea.

INSERÇÃO II - caracteriza-se pela análise multidimensional do processo educacional em sala de aula e nos demais espaços educativos, abordando propostas de construção do conhecimento centrado no processo ensino-aprendizagem percebido em todas as suas dimensões: características, etapas, tipologias e teorias, seus fatores de influência e problemas, suas práticas didático-pedagógicas, suas práxis avaliativas.

INSERÇÃO III - intervenção do profissional em formação no processo educativo garantindo o aperfeiçoamento da evolução e das especificidades dos processos utilizados na educação básica, focalizando, sobretudo, o conhecimento específico da área das ciências, permeado por princípios filosóficos e políticos que sustentam a docência emancipatória. (UFPR, 2010a, p. 98)

O estágio no Projeto da UFPR Litoral ganha uma dimensão ampliada ao ser percebido não só como um recurso de aprendizagem da profissão na formação inicial, mas, também, como um recurso para formação continuada de professores.

Art. $3^{\circ}$ - Constituem objetivos gerais do Estágio Curricular Supervisionado:

I - Promover a articulação entre a Universidade Federal do Paraná, o Núcleo Regional de Educação de Paranaguá e as Secretarias Municipais de Educação do litoral paranaense, a fim de desenvolver atividades de pesquisa, extensão e formação continuada por meio do Estágio Curricular Supervisionado. (UFPR, 2011, p. 57)

A proposta da Universidade de estabelecer relações articuladoras de formação com o campo que recebe os futuros docentes caminha na direção de uma formação inicial em que a universidade e as escolas estabeleçam processos mútuos de formação/investigação: 
Art. $2^{\circ}$ - ... Parágrafo único: O período em que os estagiários estão em campo contribui para o seu desenvolvimento acadêmico, retroalimenta temáticas a serem trabalhadas no curso e potencializa parcerias entre a universidade e a comunidade, subsidiando pesquisas de estudantes e professores do curso, bem como a realização de atividades de extensão, de formação continuada, conforme preconiza o PPP do Setor Litoral. (UFPR, 2011, p. 57)

Destaca-se que essa relação de parceria investigação/formação deve contemplar possibilidades formativas, não apenas aos professores da educação básica que, ao receberem a universidade, se beneficiam com os conhecimentos produzidos nessa, como também à universidade e seus docentes, que precisam reconhecer nos professores da educação básica sujeitos que produzem conhecimento e com quem podem aprender. Os professores que atuam na formação inicial na graduação encontramse muitas vezes distanciados do campo, ou, em alguns casos, nunca exerceram a profissão no contexto profissional (educação básica) para o qual estão formando os futuros docentes.

$\mathrm{Na}$ proposta da UFPR Litoral fica evidenciada a compreensão do estágio como possibilidade de ofertar formação continuada para a educação básica, mas fica menos clara a compreensão deste como uma modalidade de formação continuada para seus docentes.

$\mathrm{Da}$ análise empreendida no que se refere aos estágios, percebeu-se que o currículo, tal como é concebido na UFPR Litoral, em que todos os momentos curriculares têm a realidade como ponto de partida e de chegada, mediatizados pela teoria, contempla a formação em que o estágio "deixaria de ser um apêndice do currículo e passaria a integrar o corpo de conhecimentos do curso de formação de professores" (Pimenta \& Lima, 2012, p. 55). No entanto, mesmo a formação prática estando presente e de forma integrada, articulada, ao longo de toda a proposta curricular, constituindo-se em um dos diferenciais desse projeto, o estágio encontrase inserido no currículo dessas licenciaturas como um componente curricular específico para atendimento da legislação. Indaga-se, dessa forma, se a inclusão de um componente extra para os estágios nessa proposta não se constituiria em uma redundância, ou se não se tomaria como uma conformação ou, quem sabe, uma "deformação" do projeto em atendimento às orientações de caráter legal.

Considera-se que o estágio organizado nos moldes da tradição e normatizado conforme a legislação pode se constituir em um impedimento para a superação das críticas e para a construção de novas estratégias de articulação entre os saberes acadêmicos e os saberes profissionais.

Como nos lembram Nascimento, Almeida, e Passos (2016):

o mais importante na formação inicial consistiria em aprender a aprender com a experiência, o que demanda avanços nos modos de traduzir essa lógica nas propostas curriculares, no âmbito da formação inicial, ou seja, é necessário constituir itinerários formativos que possibilitem romper com uma visão estática que tem sido predominante no modo de conceber a relação entre a formação e o trabalho que pode ser traduzida em um somatório de momentos formais não articulados. (p. 11)

Defendemos que, enquanto conservarmos organizações curriculares que funcionam por especialização e fragmentação, dificilmente conseguiremos desfazer o nó do estágio que deflagra a dicotomização entre teoria e prática. Uma possível via para conceder ao componente prático da formação o estatuto de epistemologia passará pela revisão do paradigma curricular técnico-disciplinar. 


\subsection{MODELOS DE FORMAÇÃO}

Qualquer reflexão sobre inovação curricular na formação de professores só fará sentido se questionarmos os modelos de formação subjacentes a essas iniciativas.

García (1999) propõe cinco orientações para a formação de professores.

a. Orientação acadêmica: essa concepção prioriza a formação do especialista em uma determinada área. O programa foca a transmissão de conteúdos acadêmicos-científicos.

b. Orientação tecnológica: foca a formação na competência técnica, nas destrezas e estratégias necessárias para ensinar. O professor é visto como um técnico que aplica ou transmite com destreza um conhecimento pré-definido ou elaborado fora dele. São importantes nessa orientação a definição de condutas, objetivos de treino e avaliação precisa dos resultados.

c. Orientação personalista: a pessoa é o centro dessa orientação. O autoconhecimento, a visão de si mesmo e a forma como interage com as situações são essenciais nessa proposta. O papel da formação consiste em promover o desenvolvimento pessoal e valorizar o caráter pessoal do ensino ajudando o futuro professor a desenvolver estratégias personalizadas diante do fenômeno educativo.

d. Orientação prática: valoriza a experiência como fonte de aprendizagem para a docência. Considera que a docência é uma atividade complexa, caracterizada pela ambiguidade e incerteza, com situações singulares não previstas na teoria, cuja aprendizagem é favorecida mediante a experiência adquirida no desempenho com os práticos da profissão. A orientação prática pode apresentar-se na abordagem tradicional e na abordagem reflexiva sobre a prática.

e. Orientação social-reconstrucionista: mantém uma estreita conexão com a teoria crítica aplicada ao ensino e ao currículo. Contempla a análise do contexto social no processo de ensinoaprendizagem, adotando uma perspectiva do conhecimento como construção social.

Esses modelos de formação tem sido consensuados por boa parte dos pesquisadores da área. Santos (2007), na linha do pensamento de Ken Zeichner, propõe a tradição acadêmica, a tradição da eficiência social, a tradição desenvolvimentista e a tradição reconstrucionista social. Tardif (2011) apresenta o tecnólogo, o prático reflexivo e o modelo do ator social. DinizPereira (2007) propõe os modelos técnicos, modelos práticos e modelos críticos de formação docente.

A experiência em análise traz fortes indícios de superação dos modelos acadêmicos e técnicos considerados dominantes na formação de professores, para inspirar-se em uma orientação crítica:

A sociedade, frente ao avanço tecnológico decorrente da ciência moderna que funda a racionalidade técnica, inspiradora da formação universitária ocidental, apresenta nas mais diversas áreas sinais de crise... A crise do paradigma dominante abre possibilidade para questionamentos e reflexões sobre os processos de educação e formação que foram historicamente nele inspirados. Deixa de ser natural, ou deixa de ser naturalizada, a construção de um currículo educacional tão somente a partir de um olhar técnico da área de conhecimento que envolve. Ao mesmo tempo é possível questionar a compreensão da docência e da discência especialmente na dimensão técnica. (UFPR, 2010b, p. 12)

No centro de um modelo crítico de formação de professores está uma atitude voltada para a transformação social. A criação da UFPR Litoral surge a partir da compreensão da responsabilidade social da instituição em trazer desenvolvimento econômico, social, educacional 
para uma região à margem do desenvolvimento sustentável e dos valores da justiça e equidade social. A UFPR Litoral funda seu projeto numa visão educacional comprometida com a transformação social, ambiental e com a qualidade de vida das pessoas.

A UFPR - Setor Litoral se assume como uma instituição que tem seu papel e prática social referida a sociedade, portanto não existe para si. Toma a sociedade ou realidade social como referência, apercebe-se como uma instituição que não está acima ou abaixo, mas junto com as demais instituições sociais... se insere assim na realidade regional do litoral paranaense e do Vale do Ribeira, para desenvolver, juntamente com essas comunidades, um projeto que tem como pressuposto a ação coletiva e a ação de protagonista de seus sujeitos, que busca integrar a educação pública em todos os seus níveis, desde a educação infantil até a pós-graduação, e pretende contribuir decisivamente para o desenvolvimento científico, econômico, ecológico e cultural. Deseja, a partir dessas intencionalidades, fomentar a interação entre a comunidade da UFPR - Litoral e a comunidade litorânea, objetivando a construção de um novo ciclo de desenvolvimento sustentável nesta região. (UFPR, 2010b, p. 16)

Os princípios de um modelo de formação crítica com forte compreensão do seu papel de transformação social encontram-se, ainda, ilustrados nos objetivos assumidos nas licenciaturas:

- Formar profissionais com compreensão do papel social e político de sua profissão;

- Desenvolver o processo formativo, tendo a realidade concreta local como ponto de partida e de problematização e intervenção viabilizada mediante a ação investigativa, diálogo com o sistematizado e intervenção social;

- Oferecer cursos de licenciatura e programas de capacitação para os professores de ensino fundamental e médio da rede pública, orientados para o desenvolvimento educacional, sociocultural e econômico da região;

- Oferecer formação emancipatória que possibilite a construção de conhecimentos para o autogerenciamento de suas atividades, gestão de pessoas, eticidade nas relações sociais, capacidade empreendedora e ação interventiva;

- Construir e difundir conhecimentos, entendendo-os em uma lógica dialética do global com o local, a partir de suas realidades concretas, possibilitando que os conhecimentos locais tencionem os globais e estimulem a criação e fortalecimento da cultura local em um contexto de relações democráticas, éticas e de participação;

- Trabalhar de forma articulada com a sociedade civil e os governos municipal, estadual e federal com o propósito de articular políticas públicas já existentes com as necessidades e possibilidades da região.

- Promover a participação da população, visando à difusão das conquistas e dos benefícios resultantes do conhecimento e da pesquisa gerados na instituição, num esforço de mobilização e de organização em que a população possa se apropriar como sujeitos ao lado dos educadores.

Observa-se uma sincronicidade entre os objetivos expressos e as metas propostas por Zeichner e Flessner (2011) para programas de preparação de professores numa orientação crítica: apresentar consciência sociocultural sendo capaz de reconhecer que a percepção da realidade varia de acordo com o lugar que o indivíduo ocupa na ordem social; ter uma visão afirmativa diante da diversidade dos estudantes, reconhecendo possibilidade de aprendizagem 
em todos, ao invés de considerar as diferenças como problemas a superar; reconhecer-se como responsável e capaz de promover a mudança educacional que tornará as escolas responsivas a todos os estudantes; conhecer a vida dos estudantes, incluindo o conhecimento de suas comunidades.

Percebe-se, nesses ideais, um componente que incentiva os professores a atuarem como agentes de inovação dentro e fora da escola e a desenvolver práticas pedagógicas a partir de realidades conhecidas e significativas para os alunos. Desse modo, coloca-se uma mudança, também, para o papel e perfil dos professores que formam esses profissionais na universidade. Para Zeichner e Flessner (2011), uma das iniciativas mais importantes para fortalecer a formação de professores para a justiça social consiste em que os formadores de docentes incorporem em seu trabalho a mesma postura que esperam que seus alunos adotem. Essa compreensão é manifestada nas licenciaturas da UFPR Litoral:

Esse projeto curricular procura tomar como ponto de partida o contexto no qual o curso está inserido, a história de vida dos professores em formação, matrizes culturais a partir das quais as vidas desses estudantes foram construídas, seus desafios, e suas particularidades em articulação com a realidade social. Ao fazer isso, objetiva instrumentalizá-los para agir da mesma forma com seus futuros estudantes no contexto sociocultural em que vivem. (UFPR, 2010b, p. 39)

\subsection{PROCEDIMENTOS METODOLÓGICOS}

Em relação à metodologia, observa-se nuances nos três cursos. No Projeto Pedagógico de Artes, é dedicado um tópico para a fundamentação teórico-metodológica, onde constam aspectos referentes à característica integradora do currículo, privilegiando a interdisciplinaridade e pautando a formação na realidade concreta dos estudantes. Porém, não encontramos uma explicitação clara no que diz respeito à metodologia.

O Projeto Pedagógico do Curso de Linguagem e Comunicação (UFPR, 2011) declara que a metodologia do curso prevê: articular teoria e prática; tecer relações entre os diferentes eixos de formação e áreas de conhecimento; tecer relações entre o saber acadêmico e a realidade social; conhecer e selecionar materiais didáticos e novos recursos educacionais ao Ensino Fundamental e Médio; construir materiais didáticos a serem utilizados em instituições de ensino; participar de encontros, seminários, congressos e palestras; interagir criticamente com o conhecimento veiculado na Internet; refletir criticamente sobre o fazer pedagógico na própria instituição e fora dela; participar de projetos de intervenção em instituições escolares ou não. Declara, ainda, que a metodologia adotada no Curso procura priorizar posturas investigativas críticas, bem como a capacidade de elaboração própria. Para tal, o trabalho poderá ser desenvolvido a partir de diferentes estratégias, tais como: aulas expositivas dialogadas, sempre acompanhadas da reflexão (oral e escrita), do debate e da relação com as situações práticas; seminários; dinâmicas de análises, dando ênfase aos diferentes aspectos estudados articulados à realidade social e educacional brasileira; veiculação dos registros escritos de conteúdos, discussões e pesquisas na turma; construção de portfolio que sistematize os conteúdos trabalhados, análises, relatórios e outras atividades desenvolvidas.

O Projeto Pedagógico de Ciências, no item referente à metodologia, argumenta que a Ciência deve ser apresentada como construção coletiva da humanidade, sendo importante formar sujeitos reflexivos, participativos e cidadãos. Frente a isso, faz a opção preferencialmente pela metodologia de projetos por trazer uma nova perspectiva para o processo de ensino-aprendizagem. 
Têm-se como metas com esse tipo de metodologia que o aluno aprenda no processo de produzir, de levantar dúvidas, de pesquisar, e de criar relações, que incentivam novas buscas, descobertas, compreensões e reconstruções de conhecimento. $\mathrm{O}$ professor deixa de ser aquele que ensina para ser um mediador na (re)construção do conhecimento, para que o aluno possa encontrar sentido naquilo que está aprendendo. O papel do professor nesse caso é o de problematizador, já que na metodologia por projeto a pesquisa é o princípio educativo. Os momentos coletivos com os estudantes não podem prescindir do diálogo. (UFPR, 2010a, p. 19)

Encontra-se, no PPC, a declaração de que a metodologia de projetos favorece articulações interdisciplinares e extrapola o tempo e o espaço físico convencional. Há o esclarecimento de que a referida metodologia não comporta passos rígidos na sua aplicação, mas explicita alguns princípios que o curso observa na condução do trabalho com projetos.

No primeiro semestre são desenvolvidas atividades, tais como reflexão e discussão de vídeos, textos, palestras e saídas de campo, entre outras, com o objetivo de familiarizar o aluno com o PPP do Setor, do Curso e com a metodologia de projetos. A partir do reconhecimento regional e com a mediação do professor responsável pela turma, podem escolher o tema do projeto, sempre levando em consideração o objetivo e a temática da turma. A seguir, o coletivo realiza um planejamento das atividades que poderão ser desenvolvidas para alcançar o objetivo. $\mathrm{O}$ processo é exemplificado no PPC:

se o projeto de estudo for, por exemplo: "metodologias de ensino de ciências utilizadas nas escolas locais", a partir das temáticas da série contidas no PPC o coletivo buscará estabelecer, por exemplo: bibliografias essenciais a serem estudadas, locais e pesquisas a serem investigados, professores que serão convidados e outras atividades. Ao se aproximar do final do semestre, volta-se aos objetivos e ao cronograma a fim de rever/readequar o planejamento. Além disso, tudo o que acontece é registrado em portefólios produzidos individualmente pelos estudantes. Ao final do semestre então se avalia coletivamente o desenvolvimento do projeto e delineia-se uma perspectiva de projeto para o semestre seguinte. No semestre seguinte retoma-se, problematiza-se, vai ao PPC para garantir o atendimento às temáticas e aos objetivos e segue com um novo projeto ou até continuidade do anterior se for o caso. (UFPR, 2010a, p. 21)

Diante da complexidade da metodologia que exige um acompanhamento constante, conforme declarado no PPC, ocorrem reuniões pedagógicas semanais para que estudantes e professores relatem o andamento dos projetos das turmas, o que pode resultar em reavaliação do projeto.

A análise documental nos permitiu observar que nos cursos de Artes e Linguagem e Comunicação não foi possível verificar um redimensionamento significativo em relação à metodologia. $\mathrm{O}$ curso de Ciências deu um passo expressivo em direção à reatualização metodológica. Ao fazer opção pela metodologia de projetos, caminha na direção do PPP da instituição, que tem uma organização pedagógica fundamentada em projetos, e na direção de metodologias ativas de abordagem problematizadora.

\section{INDICADORES DE INOVAÇÃO: SÍNTESE INTERPRETATIVA}

Consideradas as diferenciações nas ênfases e níveis de consolidação no processo de mudança nos cursos analisados, ao concluirmos o estudo, pode-se afirmar que o projeto das licenciaturas da UFPR Litoral manifesta movimentos de mudança em um conjunto de pontos que 
assumem significado de indicadores de inovação para a formação inicial de professores.

Ao colocar em ação os princípios de uma educação emancipatória e de uma proposta pedagógica fundamentada em projetos, o programa das licenciaturas da UFPR Litoral rompe com a organização e o paradigma curricular técnico-linear-disciplinar. Os cursos apresentam uma estrutura curricular inovadora que abre mão das disciplinas, estabelecendo como componentes curriculares as Interações Culturais Humanísticas, os Fundamentos Teórico-Práticos e os Projetos de Aprendizagem.

Esse novo currículo, com características da organização curricular integrada e de identificação com as abordagens curriculares críticas e pós-críticas repercute em significativas alterações em outros aspectos que historicamente vem se mostrando problemáticos na formação de professores, tais como: modelos de formação, saberes docentes, atividades práticas/estágio e reatualização metodológica. Consideradas as diferenciações nas ênfases e níveis de consolidação no processo de mudança nos três cursos analisados, conforme já apontados na análise de cada uma das categorias, observa-se um importante movimento de transição entre a tradição e a transformação, em que é colocado em ação um conjunto de ideias-força que assume significado de indicadores de inovação para a formação inicial de professores.

A partir dessa pesquisa documental, circunscrita ao currículo prescrito, pretendeu-se trazer para a discussão curricular uma alternativa de re-invenção que uma instituição e/ou sujeitos coletivos vêm arriscando nas suas possibilidades de finitude e inconclusão. Procuramos captar no currículo prescrito o que nele se encaminha para a criação e reinvenção, tornando mais visíveis essas iniciativas que portam o germe de superação dos modos dominantes de se fazer o currículo e a educação. Ao concluirmos este estudo, sabemos não ter esgotado todos os direcionamentos e sentidos da mudança em andamento nos cursos de licenciatura da UFPR Litoral. Contudo, temos motivos para acreditar que se trata de uma mudança de largo alcance, na medida em que a inovação pressiona os outros níveis educacionais a rever seus currículos. Isso ocorre seja por meio da visão da universidade que tem nas metas da educação transformadora o compromisso de interagir com as escolas de educação básica da região, seja por meio dos protagonistas da proposta, alunos e professores que interagem com as escolas da educação básica e que idealizam esse futuro.

Os resultados da pesquisa indicam que a proposta da UFPR Litoral traz novos contornos para o campo da teoria e das práticas curriculares dos programas de formação inicial, ao ser capaz de, como diz Nóvoa (2009), superar a inflação discursiva e colocar em ação na prática um futuro que há tempos vem sendo anunciado.

\section{REFERÊNCIAS}

Anyon, J. (2011). Somente a pedagogia crítica não basta: Educação voltada à justiça social, à participação política e à politização dos estudantes. In M. Apple, W. Au, \& L. A. Gandin (Eds.), Educação crítica: Análise internacional (pp. 430-436). Porto Alegre: Artmed.

Apple, M. W. (2003). Poder, significado $e$ identidade: Ensaios de estudos educacionais críticos. Porto: Porto Editora.

Beane, A. J. (2003). Integração curricular: A essência de uma escola democrática. Currículo sem fronteiras, 3(2), 91-110.

Bernstein, B. (1995). Estruturação do discurso pedagógico: Classe, códigos e controle. Petrópolis: Vozes.

Carbonell, J. (2002). A aventura de inovar: A mudança na escola. Porto Alegre: Artmed.

Cunha, M. I. (2010). Lugares de formação: Tensões entre a academia e o trabalho docente. In A. Dalben, J. Diniz, L. Leal, \& L. Santos (Orgs.), Convergências e tensões no campo da formação 
docente: Didática, formação de professores $e$ trabalho docente (pp. 129-149). Belo Horizonte: Autêntica.

Diniz-Pereira, J. E. (2007). Paradigmas contemporâneos da formação docente. In J. V. A. Souza (Org.), Formação de professores para a educação básica: Dez anos de LDB (pp. 252-263). Belo Horizonte: Autêntica.

Diniz-Pereira, J. E., \& Amaral, F. (2010). Convergências e tensões nas pesquisas e nos debates sobre as licenciaturas no Brasil. In A. Dalben, J. Diniz, L. Leal, \& L. Santos (Orgs.), Convergências e tensões no campo da formação docente: Didática, formação de professores $e$ trabalho docente (pp. 527-550). Belo Horizonte: Autêntica.

Freire, P. (2005). Pedagogia do oprimido (43a ed.). Rio de Janeiro: Paz e Terra.

García, C. M. (1999). Formação de professores para uma mudança educativa. Porto: Porto Editora.

Gatti, A. B. (2010). Licenciaturas: Crise sem mudança? In A. Dalben, J. Diniz, L. Leal, \& L. Santos (Orgs.), Convergências e tensões no campo da formação docente: Didática, formação de professores e trabalho docente (pp. 485-508). Belo Horizonte: Autêntica.

Gatti, A. B., \& Nunes, M. R. N. (Orgs.). (2009). Formação de professores para o ensino fundamental: Estudo dos currículos das licenciaturas em Pedagogia, Língua Portuguesa, Matemática e Ciências Biológicas. Coleção TEXTOS FCC, 29(mar). São Paulo: FCC.

Giroux, H. (1997). Os professores como intelectuais: Rumo a uma pedagogia crítica da aprendizagem. Porto Alegre: Artmed.

Imbernón, F. (2001). Formação docente $e$ profissional: Formar-se para a mudança e a incerteza. São Paulo: Cortez.

Keller-Franco, E. (2014). Movimentos de mudança: Um estudo de caso sobre inovação curricular em cursos de licenciatura da UFPR Litoral (Tese de doutorado). Pontifícia Universidade Católica de São Paulo - PUC-SP, São Paulo, Brasil.
Keller-Franco, E., \& Masetto, M. T. (2017). Avanços curriculares na formação inicial de professores. Revista Contrapontos-Eletrônica, 17(3), 529-551. doi:10.14210/contrapontos. v17n3.p529-551

Lopes, A. C., \& Macedo, E. (2011). Teorias de currículo. São Paulo: Cortez.

Lüdke, M., \& André, M. E. D. A. (2013). Pesquisa em educação: Abordagens qualitativas (2 $2^{\mathrm{a}}$ ed.). São Paulo: EPU.

Masetto, M. T. (Org.). (2012). Inovação no ensino superior. São Paulo: Edições Loyola.

Nascimento, M. G., Almeida, P. C. A., \& Passos, L. F. (2016). Formação docente e sua relação com a escola. Revista Portuguesa de Educação, 29(2), 9-34.

Nóvoa, A. (2009). Professores: Imagens do futuro presente. Lisboa: Educa.

Oliveira, I. B. (2004). As artes do currículo: O currículo integrado. In I. B. Oliveira (Org.), Alternativas emancipatórias em currículo (pp. 9-25). São Paulo: Cortez.

Oliveira, I. B. (2005). Redes de conhecimento e práticas emancipatórias no cotidiano escolar GRPesq Currículo e Cotidiano Escolar. In I. B. Oliveira \& A. C. Amorim (Orgs.), Sentidos de currículo: Entre linhas teóricas, metodológicas $e$ experiências investigativas (pp. 24-27). Campinas: GT Currículo, Anped. Disponível em: http://www.fe.unicamp.br/gtcurriculoanped/ publicacoes.html

Pimenta, S. G., \& Lima, M. S. L. L. (2012). Estágio e docência (7a ed.). São Paulo: Cortez.

Romanowski, J. P., \& Martins, P. L. O. (2010). Situação atual das licenciaturas: $\mathrm{O}$ que indicam as pesquisas a partir de 2000. In A. Dalben, J. Diniz, L. Leal, \& L. Santos (Orgs.), Convergências e tensões no campo da formação docente: Didática, formação de professores e trabalho docente (pp. 509-526). Belo Horizonte: Autêntica.

Santomé, J. T. (1998). Globalização e interdisciplinaridade: $O$ currículo integrado. Porto Alegre: Artes Médicas.

Santos, L. L. (2007). Paradigmas que orientam a formação docente. In J. V. A. Souza (Org.), 
Formação de professores para a educação básica: Dez anos de LDB (pp. 235-252). Belo Horizonte: Autêntica.

Silva, T. T. (2007). Documentos de identidade: Uma introdução às teorias do currículo (2a ed.). Belo Horizonte: Autêntica.

Tardif, M. (2011). Saberes docentes e formação profissional (12a ed.). Petrópolis: Vozes.

UFPR, Unidade Litoral. (2008). Projeto político pedagógico da UFPR Litoral. Matinhos.

UFPR, Unidade Litoral. (2010a). Projeto político pedagógico de curso - Licenciatura em Ciências. Matinhos.

UFPR, Unidade Litoral. (2010b). Projeto político pedagógico de curso - Licenciatura em Artes. Matinhos.

UFPR, Unidade Litoral. (2011). Projeto político pedagógico de curso - Linguagem e Comunicação. Matinhos.

Zeichner, K. M., \& Flesner, R. (2011). Educando os professores para a educação crítica. In M. W. Apple, W. Au, \& L. A. Gandin (Orgs.), Educação crítica: Análise internacional. (pp. 331-348) Porto Alegre: Artmed.

\section{TEACHER DEVELOPMENT CHANGING PROCESSES: ANALYSIS OF A CURRICULUM INNOVATION PROPOSAL IN INITIAL TEACHER EDUCATION COURSES}

\section{Abstract}

The recurring complaint that the initial training has not offered appropriate responses to the new demands of teachers' work in contemporary society incites the review of curricula that aims at these professionals' development. In this context, the present study focuses on the critical analysis of an alternative curriculum organization developed in undergraduate courses at a Brazilian public university. The chosen guiding question was to investigate to what extent the proposal that has been implemented in such courses brings indicators to curriculum innovation in initial teacher development. The methodological approach adopted was the qualitative research. The data was obtained primarily through documental analysis. Data analysis comprised three steps: pre-analysis; exploitation of the material; data analysis and interpretation. The data indicates that the curriculum reform in progress manifests itself in changing movements in a set of core and relevant elements such as curriculum design and organization, teaching knowledge, models for teacher development, practical activities/ training and teaching-learning methodology.

KEYWORDS: Initial teacher education; Curricular innovation; Undergraduate courses 
FORMACIÓN DOCENTE EN PROCESOS DE CAMBIO: ANÁLISIS DE UNA PROPUESTA DE INNOVACIÓN CURRICULAR EN LOS CURSOS DE

\section{I C E N C I A T U R A}

\section{RESUMEN}

La recurrente denuncia de que la formación inicial no está atendiendo las nuevas exigencias de trabajo de los profesores en la sociedad contemporánea plantea la cuestión sobre la revisión de los currículos que gradúan a dichos profesionales. En este contexto, el presente estudio se fija en el análisis crítico de una ordenación curricular alternativa que se desarrolla en cursos de licenciatura de una universidad pública brasileña. Se ha elegido como tema orientador investigar en qué medida la propuesta que se implementa en tales cursos vincula referentes para la innovación curricular en la formación inicial de profesores. Se toma como camino metodológico el abordaje cualitativo de investigación. Con el objetivo de colectar datos se privilegió un análisis documental. El análisis de datos estuvo compuesto por tres etapas: pre-análisis; estudio del material; tratamiento de los resultados obtenidos y interpretación. Los datos indican que la innovación curricular en marcha se manifiesta con el alzamiento a cambios en un conjunto de elementos centrales y relevantes, así como concepción y ordenación curricular, saberes docentes, modelos de formación, actividades funcionales/ práctica laboral y metodología enseñanza-aprendizaje.

\footnotetext{
${ }^{\text {I }}$ Programa de Pós-Graduação: Mestrado Profissional em Educação, Centro Universitário Adventista de São Paulo (UNASP), Brasil. Orcid: 0000-0003-1795-8947

${ }^{\text {II }}$ Programa de Pós-Graduação em Educação: Currículo, Pontifícia Universidade Católica de São Paulo (PUC-SP), Brasil.
} 